\section{Psychiatry for the person - the view from Asia}

Sir:

The editorial by George Christodoulou et al (2008) on 'Psychiatry for the person' and the response by Jeremy Holmes (2008) have been read with avid interest on this side of the globe. Listening to previous presentations on this topic at Asian meetings of the World Psychiatric Association (WPA), we were often left with a sinking feeling that they resonate well with our work but could be better. For the Institutional Programme on Psychiatry for the Person (IPPP) to succeed, there should be more participation from developing countries. The marketplace of ideas should not be confined to academics in Europe and North America and ignoring the rich experience of clinicians in Chennai, Singapore or Batu Pahat.

Professor Holmes understands that the practice of psychological therapy is different in Asia - the philosophies of Confucius and Lao Tze have immense influence on East Asian psychological therapy. The challenge is how to translate an erudite document in the IPPP into clinical practice, not just for psychiatrists but also for other doctors and medical students. Psychiatry for the person should also be practised at the primary care level; in Singapore two family physicians have crafted an innovative narrative approach in psychological therapy for primary care doctors, focusing on the centrality of personhood (Cheong \& Goh, 2008). Psychiatry for the person should not be a hollow catchword and future psychiatrists should not merely be pharmacotherapists, with psychological therapy outsourced to social workers, counsellors and psychologists.

Fortuitously, some of these issues will be discussed in a forthcoming meeting in Singapore on 23-24 February 2009. The TOP (Teachers Of Psychiatry) Conference has the support of the Royal College of Psychiatrists (UK, Western Pacific Division), Pacific Rim College of Psychiatrists and Asian Federation of Psychiatric Associations. This is an open letter to welcome the WPA to participate. Further information on this conference can be obtained from pcmkeh@nus.edu.sg.

Professor Kua Ee Heok Head, Department of Psychological Medicine, National University of Singapore, email pcmkeh@nus.edu.sg

Cheong, P. Y. \& Goh, L. G. (2008) The Singapore Family Physician. College of Family Physicians, Singapore (in press).

Christodoulou, G., Fulford, B. \& Mezzich, J. E. (2008) Psychiatry for the person and its conceptual bases. International Psychiatry, 5, 1-3.

Holmes, J. (2008) Psychiatry for the person. International Psychiatry, 5, 50.

\section{Competency-based training schemes in psychiatry}

S-At its 2006 annual forum in Riga, the European issued its first statement on competency-based training and assessment in psychiatry. The EFPT, which represents national associations of psychiatric trainees from across Europe, is broadly in favour of competency-based training if it improves the standard of psychiatric education and is not overly bureaucratic.

Competency-based training schemes in psychiatry are currently being introduced in Denmark, the Netherlands,
Sweden and the UK, and there are plans for similar changes to training in a number of other European countries. The EFPT believes there are significant opportunities for crossEuropean collaboration and mutual learning between the countries introducing these changes. The EFPT also very warmly welcomes the decision of the Board of Psychiatry of the Union Européenne des Médicines Spécialistes (UEMS) to set up a working group to look at common competencies in psychiatry required for all specialists working within the European Union (EU), based on the UEMS document 'A profile of a psychiatrist'.

We, as European trainees, believe that well designed, properly funded and wisely implemented reforms that have the potential to improve training will also improve the mental health of Europe. The fact that many EU countries are taking a similar approach and implementing similar changes at the same time also provides a unique opportunity to agree some common standards, to share and develop common assessment tools, and to strengthen the specialty. The adoption of more similar approaches in training and assessment may also facilitate greater cross-EU collaboration and exchange, for example making it far easier for a trainee from one country to spend a period of training in another country if the competencies and means of assessing them are similar.

Ian Soosay

Chairperson, Working Group on Competency-Based Training, European Federation of Psychiatric Trainees, email r.soosay@ucl.ac.uk

\section{Association of European Psychiatrists (AEP)}

C. Your readers may be interested to know that - the Association of European Psychiatrists (AEP) held its 16th Annual Congress in Nice, France, 5-9 April 2008. There were almost 3000 delegates from 57 countries. The theme was 'Pathways to Integrative Care.'

The AEP Young Psychiatrists Committee also organised a parallel series of high-quality lectures and informal sessions aimed specifically at trainees and young psychiatrists. Among these, Povl Munk-Jørgensen, editor of Acta Psychiatrica Scandinavica, provided an informative lecture on getting research published. There were also informal discussions with Professor Wolfgang Fleischhacker on how to embark upon a career in research and Professor Norman Sartorius on mental health issues across Europe. The Committee awarded 15 scholarships to trainees and young psychiatrists from across Europe. These awards enabled enthusiastic trainees and young psychiatrists to attend the conference by providing financial assistance with travel and accommodation. Scholarship winners also received 1 year's free AEP membership and admission to a course for continuing medical education at the Congress.

We look forward to the 17th AEP European Congress of Psychiatry, entitled 'New Diagnostic Approaches in Psychiatry: Relevance for Research and Practice in Europe', which will take place in Lisbon, Portugal, 24-28 January 2009 (see http://www.kenes.com/aep2009).

Iris Calliess, ${ }^{1}$ Kai Treichel ${ }^{1}$ and Alexis Bowers ${ }^{2}$ ${ }^{1}$ Young Psychiatrists Committee; ${ }^{2}$ AEP scholarship winner, emaildralexisbowers@hotmail.com 